\title{
A TAREFA CRIATIVA DA ÉTICA
}

The creative task of ethics

Ildefonso Camacho *

Os problemas éticos que se colocam no nosso mundo não são poucos. Pode-se tentar enumerá-los: isso resultaria numa lista abundante e quase interminável, e seguramente não ficaríamos satisfeitos, com a impressão de que algum ficou esquecido. Mais complicado ainda seria propor-se ordená-los em função de sua importância: dependendo das pessoas que o fizessem, priorizar-se-iam uns ou outros. Por outro lado, muitos deles não são independentes entre si, de forma que uma mera enumeração não daria conta da realidade. Por isso, pareceu-nos melhor caminho buscar algumas questões que poderiam ser como que articuladoras de outras. Com este enfoque nos dispomos a avançar nestas páginas.

Um primeiro eixo articulador poderia ser o enfoque geral da ética e o lugar que ocupa na vida humana e na sociedade. Frente àquela ética unitária e homogênea, muito dependente de uma autoridade indiscutida, o pensamento moderno produziu um recentramento para colocar o sujeito humano como referência última. Não cabe exagerar as consequências deste giro antropológico. Ora, daí seguiu-se uma subjetivização da ética, que agora não se remete somente a normas objetivas, sobre as quais não é fácil chegar a consensos estáveis; ressalta-se ademais, e com razão, o papel da liberdade e da responsabilidade da pessoa. Se a ética se restringiu durante muito tempo à discussão das normas, à sua justificação

\footnotetext{
* Faculdad de Teología de Granada, Granada, España.
} 
até alcançar consensos que antes facilitavam o recurso à autoridade, hoje a norma não é tudo: em seguida, deve-se considerar como cada sujeito a aplica a uma situação concreta. O papa Francisco, com sua insistência no discernimento em coerência com a mais autêntica tradição inaciana, tem contribuído para que também a Igreja se sensibilize quanto a esta dimensão, muitas vezes muito esquecida.

Porém esta subjetivização da ética tem também seus riscos, que não seria correto ignorar: o de derivar em certo relativismo deixando o sujeito como dono absoluto de sua ética numa má compreensão do que é o respeito às pessoas e a tolerância. A mentalidade pós-moderna, com seu pouco apreço pela razão, por muito que intentemos complementá-la com o coração (a razão cordial), pode conduzir a um relativismo que torna difícil a convivência numa sociedade plural.

Isto a que chamamos de subjetivização da ética tem a ver também com o pluralismo de cosmovisões, culturais e religiosas, que hoje se encontram num mundo cada vez mais globalizado. $O$ pluralismo não é de hoje, porém hoje somos mais conscientes dele porque vivemos nele imersos dada a mobilidade de nosso mundo. A necessidade de configurar uma convivência num mundo tão plural nos coloca diante do desafio de gerir o pluralismo ético, a partir da convicção de que nenhuma ética particular tem o direito de impor-se sobre as outras. E não podemos deixar de indicar que o aceitar este pluralismo ético e compreender o papel que lhe corresponde em seu cerne é uma das questões que a Igreja não consegue resolver, e em alguns casos nem sequer de aceitar como ponto de partida.

A gestão deste pluralismo nos obriga, antes de tudo, a assumir que podemos nos situar diante dele desde uma dupla perspectiva: a da convergência e a da diversidade.

Nem tudo é diverso e incompatível: as diferentes cosmovisões têm elementos em que coincidem, e esta tem sido a fonte de uma ética universal, que todos pudéssemos admitir. Em nível da humanidade, este é o substrato do qual nasceram os direitos humanos e seu correspondente reconhecimento no terreno sóciopolítico e jurídico. Porém, este não é um terreno já esgotado. Os direitos humanos constituem um processo aberto no qual cabe avançar. Mostra disto é a progressiva sensibilização quanto ao meio ambiente e suas exigências em termos de direitos.

Cabe também perguntar se as religiões, pelo menos as grandes religiões históricas, cujas diferenças tantas energias consumimos em acentuar a ponto de provocar conflitos dramáticos e intermináveis, não teriam de buscar vias de encontro desde a fé num Deus transcendente, em contraste com a mentalidade imanente não religiosa, como uma contribuição 
própria à antropologia e, por fim, à ética. Os esforços do Parlamento das Religiões do Mundo vão nesta direção. Seria uma lástima ignorá-los ou subestimá-los.

Porém, essa eventual convergência de cosmovisões não nos pode ocultar a outra face da moeda: a diversidade. É tarefa da ética fazer com que esta diversidade seja, não fonte de intolerâncias, mas gérmen de enriquecimento para todos. Seria útil aqui recordar aquela distinção que fez Adela Cortina entre éticas de máximos e ética de mínimos. As primeiras estão em sintonia com a tradição aristotélica da felicidade como objetivo da ética: as éticas da felicidade oferecem um horizonte que expressa as aspirações mais amplas e profundas do ser humano, e admite diferentes versões segundo tradições religiosas ou ideológico-culturais. A segunda, alinhada com a ética da justiça da tradição kantiana, busca aqueles mínimos que todos temos de assumir para garantir uma convivência onde cada um possa desenvolver-se segundo suas próprias conviç̧ões (sua ética de máximos) sem converter-se em obstáculo para que os demais o façam também. Aprofundar na ética de máximos permite a cada um desenvolver-se como sujeito humano, viver em plenitude; assumir a ética de mínimos abre à vida em sociedade e ao compromisso cidadão, permite conviver no respeito e em paz.

É evidente, então, que o desenvolvimento da mentalidade moderna abriu novos caminhos para a compreensão da ética e coloca desafios e questões que nos convidam a seguir avançando a partir do diálogo baseado nas próprias convicções, porém de modo algum fechado à interpelação que nos chega do pluralismo dominante.

A partir deste eixo articulador de caráter mais geral, temos de descer agora à prática, à ética aplicada: é nesse campo que se colocam os problemas mais urgentes. Esta urgência pode estar relacionada com a consciência de que o poder humano chegou a tal ponto, graças sobretudo ao desenvolvimento da técnica, que a humanidade treme ante as ameaças que nos circundam, seja em âmbito mais geral e coletivo (mudança climática, armamento nuclear...), seja em âmbito mais próximo da manipulação da vida. Em todos eles se coloca a mesma questão: estes meios tão poderosos colocam-se a serviço de quais fins? E esta é a pergunta ética por excelência, uma pergunta que reemerge como reação frente a uma época em que estamos demasiadamente dominados pela lógica da razão instrumental, que se ocupa mais do como que do para que.

Neste novo marco há dois avanços dignos de menção que condicionam tudo o que vamos desenvolver em seguida. Um: a consciência crescente de que todo comportamento humano tem uma dimensão ética, explícita ou não reconhecida, inclusive quando se quer negar a partir dos postulados de uma neutralidade da ciência na qual se crê cada vez 
menos. Dois: a consciência de que a ética se move, não só no terreno pessoal configurando o comportamento de cada pessoa em função de suas convicções últimas, mas também no âmbito social como crítica das estruturas e instituições e propostas de revisão e transformação das mesmas. Já não vale refugiar-se numa ética estritamente pessoal (por tão importante que possa ser) argumentando que as estruturas sociais não dependem da ação de uma pessoa: a ação social, a sociedade organizada, a opinião pública e a política são os campos adequados para que este debate sobre as estruturas e instituições sociais se coloque desde uma correta compreensão da cidadania.

Se passamos já à ética aplicada, os problemas mais urgentes podem organizar-se em torno a três eixos articuladores, que não são independentes entre si: a globalização, o progresso técnico e as tecnologias da informação e as comunicações, o meio ambiente.

Comecemos pela globalização. Em princípio tem sido considerado não só como um estado de coisas, mas como um processo que avança, e que avança a ritmo inestancável. Eticamente se podem questionar os ritmos deste processo em seus diferentes níveis, ritmos que estão determinados desde jogos de poder: a globalização é mais rápida naqueles âmbitos em que se seguem mais vantagens para os poderosos (os mercados financeiros são o caso mais relevante, enquanto que a mobilidade das pessoas está muito mais restringida). Ademais, nestes momentos há sintomas de que se intentam frear os processos globalizadores, e precisamente por parte de quem mais os apoiaram. Não estamos, portanto, diante de um processo que escape a todo controle humano. Daí que resulte urgente a questão: com que critérios conduzimos o processo?, a partir de que instâncias?, como fazer que a globalização, que de fato teve e tem ganhadores e perdedores (cf. PNUD) seja uma oportunidade para todos, de acordo com a proposta de Bento XVI em Caritas in veritate?

Os efeitos da globalização poderiam sintetizar-se como uma mudança radical das relações entre economia e política. Com efeito, a evolução das sociedades no século XX conduziu a certo controle da economia por parte da política: de economias de mercado onde se postulava a mínima intervenção da política (dos poderes públicos) fomos evoluindo na direção de modelos mistos onde se confiava ao Estado a tarefa de estabelecer garantias para que a atividade econômica estivesse a serviço do bem comum e dos interesses comuns da sociedade. Por detrás deste modelo havia uma legitimação ética que também contribuiu para fazê-lo avançar. Porém, a globalização distorceu gravemente tal processo provocando que seja a economia aquela que imponha sua lei sobre a política. Como? A liberação dos mercados (chave na globalização) faz cada vez mais impotentes os Estados para regular uma atividade que se realiza sem respeitar as fronteiras, ao mesmo tempo em que carecemos de uma instituição que 
seja capaz de pôr ordem nesse grande mercado mundial segundo critérios do bem comum universal. A crise financeira que estourou em 2008 é a melhor demonstração desta ruptura.

Daí que um dos grandes desafios de nosso mundo globalizado é estabelecer uma instância mundial que realize em escala planetária algo equivalente ao que fazem, ou tentavam fazer, os Estados. Não estamos pensando num Estado mundial (extrapolação do que é o Estado nacional), mas em algo inédito, algo que está por ser criado. Caritas in veritate pôs muita ênfase na ideia de uma autoridade mundial, um tema que o pensamento cristão vinha proporcionando desde o século XIX e que encontrou um apoio muito explícito já na encíclica de João XXIII sobre a paz (Pacem in terris). Aqui se põe em jogo o papel criativo da ética, que tantas vezes ignoramos: se a ética se ocupa dos fins, as necessidades detectadas hão de ser o estímulo para buscar os meios de que carecemos.

A debilitação do Estado como modelo de organização política não pode afrontar-se com a aceitação inevitável e resignada de que está próximo o seu fim como instituição. Porém tampouco se pode esquecer que o Estado é uma instituição histórica, que tem origem no tempo. Por isso, não há razão para pensar que possui credencial de eternidade. Novamente aqui a ética tem de proporcionar criatividade para buscar fórmulas novas de organização política. Ora, é certo que esta debilitação do Estado dificulta uma das funções mais relevantes que se lhe haviam confiado e que constituíam uma razão poderosa para sua legitimação ética: a tutela e promoção dos direitos humanos. Preocupa pensar que se ponha em dúvida uma das grandes conquistas da humanidade na época moderna. Porém, há que se reconhecer que as coisas já não são as mesmas. A garantia dos direitos sociais se faz mais problemática quando as sociedades competem num mercado mundial e limitam a capacidade fiscal dos governos; ao mesmo tempo, a tutela dos novos direitos, os relacionados com o meio ambiente e a sociedade globalizada, já não está ao alcance dos Estados e está demandando uma instância que esteja acima deles. O caráter histórico dos direitos convida a não fazer deles instâncias inamovíveis nem a reduzi-los a meras aspirações humanas, porém carentes de apoio efetivo por parte da instituição política. Nos direitos há um substrato que é irrenunciável, porém nada neles é passível de revisão? Aqui há um delicado campo onde se impõe buscar novas vias a partir de uma abordagem que combine a ética, a política e o Direito.

A globalização torna inevitável abordar os problemas com uma perspectiva universal porque esta é a dimensão em que efetivamente se situam. Neste marco universal há que analisá-los para compreender seu alcance e para afrontá-los. Medidas particulares assumidas por um único Estado ou um conjunto de Estados são insuficientes. Os exemplos são inúmeros. Um, especialmente grave por aquilo que está em jogo, é o dos movimentos 
populacionais, emigrantes e refugiados, que golpeia tantas pessoas expulsas de sua terra e recebidas com desconfiança ou abertamente rechaçadas em não poucos países.

Esta inevitável perspectiva universal nos leva muito claramente a outro dos eixos articuladores que anunciamos: o tema do meio ambiente. É um terreno onde as medidas particulares surtem escasso efeito se não se apoiam em consensos internacionais. Aqui a falta de colaboração entre países ou o distanciar-se de compromissos assumidos (com exemplos muito recentes das grandes potências) põem em relevo a debilidade da organização mundial. É outro campo onde a ética tem de encorajar a busca de soluções novas, inovadoras. Por não existir uma instância de governo mundial, é importante aprofundar na colaboração entre iguais, neste caso os Estados: e a colaboração exige diálogo, negociação, busca de consensos, fidelidade aos compromissos assumidos. É uma nova forma de governar, outra via de velar pelo bem comum. E tudo isso exige o apoio de uma consciência nova de cidadania mundial, que busque equilíbrios entre os interesses particulares, qualquer que seja o nível em que se busquem, e os interesses comuns da humanidade.

A consideração do meio ambiente é outro dos eixos articuladores a que queríamos nos referir. Talvez o conceito de casa comum, que tanto tem contribuído para divulgar a encíclica de Francisco Laudato si', é o que melhor sintetiza um novo modo de relação do homem com a natureza. Vislumbramos aqui um novo paradigma ético, fruto de uma nova antropologia porque por detrás dela há também uma nova relação do homem com o meio natural: este deixa de ser objeto da conquista humana auxiliada pela técnica para converter-se em lar, casa comum, que deve ser cuidada para que acolha a todos os seres humanos, os de hoje e os das gerações futuras.

Neste terreno a ética deverá propiciar, antes de tudo, a busca de soluções técnicas para reduzir a deterioração do meio ambiente causado pela atividade humana. Porém deverá proporcionar uma mudança nos costumes e hábitos de comportamento no uso dos recursos disponíveis. E deverá propiciar, enfim, uma disposição diferente a partir da qual se entenda a própria existência e a busca da felicidade em relação com os recursos da Terra. É sabido que o modelo de desenvolvimento dos países mais avançados não é universalizável porque o planeta não poderia suportá-lo. A ética tem de fazer-se presente aqui: porque, se esta convicção é compartilhada por (quase) todos, são muitos os que não estão dispostos a abordar com a seriedade requerida as consequências que daí derivam.

Não é necessário entrar nos diversos aspectos da problemática do meio ambiente para compreender que o paradigma ético do qual impõe-se sair tem a ver com o desenvolvimento da técnica, o terceiro dos eixos articuladores 
que havíamos proposto. Os avanços da técnica na época moderna não são neutros com respeito a como o ser humano encara a própria vida. É a antropologia mesma que aponta seus efeitos. Francisco expressou isto com rigor em sua encíclica sobre a casa comum ao criticar o paradigma tecnocrático como forma de um antropocentrismo desviado. A técnica, que tantos benefícios tem proporcionado à humanidade, propiciou uma nova forma de relação com o meio ambiente: o sujeito de tal modo se converte em centro e referência última, que faz com que tudo reste subordinado a ele e reduzido a mero instrumento a seu serviço. A reflexão ética tem aqui uma imensa tarefa: revisar esta antropologia sutilmente instalada no mundo moderno, com o domínio da razão instrumental, para voltar a pôr o homem em seu lugar. Este esforço não pode ignorar tampouco como a razão instrumental tem sido sistematicamente favorecida pelo desenvolvimento da economia que deixou igualmente sua marca antropológica no fato de se referir ao homo oeconomicus.

Esta categoria de homo oeconomicus, que tem servido a tantos economistas para formalizar seus modelos, deve ser criticada por sua insuficiência analítica, mas também ética. Insuficiência analítica porque a conduta do ser humano não se explica adequadamente sob o pressuposto de que sempre busca maximizar sua utilidade, sobretudo se esta se mede em termos econômicos; insuficiência ética porque este critério não pode pôr-se como ideal que oriente o comportamento humano.

Neste particular foi Bento XVI, em sua encíclica sobre a caridade na verdade, quem convidou a repensar a lógica e a práxis econômicas introduzindo outras motivações mais complexas e mais apropriadas ao ser humano invocando o dom e a reciprocidade como motrizes que enriqueceriam a economia contemporânea. A busca de fórmulas concretas para harmonizar utilidade, dom e reciprocidade abre um campo ainda pouco explorado de diálogo entre a economia e a ética.

É hora de concluir esta panorâmica que deixará possivelmente insatisfeito a mais de um leitor. Ficará claro, pelo menos, que são muitos os problemas e que existe uma profunda inter-relação entre todos eles: por isso, no que precede, as repetições eram inevitáveis.

Se algo queremos destacar para concluir é a missão que tem a ética de abrir horizontes. A crítica de comportamentos e estruturas, que tantas vezes deve ser feita, é necessária mas não suficiente: num mundo tão aberto à mudança como o nosso, à ética corresponde uma função criativa, não só de legitimar o que merece ser legitimado ou criticar o que não se pode admitir, mas também de construir um mundo novo para o qual nem sempre vamos encontrar precedentes no passado, por muito orgulhosos que possamos nos sentir de certas conquistas das quais já se beneficia ou deveria beneficiar-se toda a humanidade. Ademais, 
é tarefa da ética não só estabelecer normas ou emitir juízos: também abrir horizontes de sentido que inaugurem novas vias para facilitar um autêntico desenvolvimento humano integral de todos os membros da família humana.

(Tradução Paulo César Barros SJ)

Editorial submetido em 07.06.2018 e aprovado em 15.07.2018.

Ildefonso Camacho é doutor em Teologia pela Facultad de Teología de Granada (1984), professor emérito de Teologia Moral da mesma Faculdade. Orcid.org//0000-0001-8685-459X. Correo electrónico: icamachol@gmail.com

Dirección: Facultad de Teología

Prof. Vicente Callao 15

E - 18011 Granada - Espanha 